\title{
Accuracy associated with the activity determination by in situ gamma spectrometry of naturally occurring radionuclides in soils
}

\author{
A. Baeza, J.A. Corbacho ${ }^{1}$, J. Guillén \\ Environmental Radioactivity Laboratory(LARUEX), Faculty of Veterinary Medicine, 10003 \\ - Cáceres, SPAIN
}

\begin{abstract}
In situ gamma spectrometry (ISGS) is a technique mainly focused on the determination of man-made radionuclides deposited on soils. It is widely used for the radioactive characterization of soils in which there has been an incorporation of such radionuclides, especially ${ }^{137} \mathrm{Cs}$. Its use for the activity determination of naturally occurring radionuclides in soils has been more limited, and the accuracy associated with those measurements has yet to be treated extensively. There are numerous factors affecting the accuracy of the activity determination of naturally occurring radionuclides, such as the assumed soil geometry, the soil's geological and mineral composition, its moisture content, etc. The present work studies the accuracy associated with the ISGS determination of the activity concentrations of natural radionuclides in soils using a portable HPGe detector. For ${ }^{40} \mathrm{~K}$ and ${ }^{232} \mathrm{Th}$ activity determinations, the uncertainties associated with ISGS are generally of the order of $15 \%$. However, ${ }^{226} \mathrm{Ra}$ activity determined from its daughters ${ }^{214} \mathrm{~Pb}$ and ${ }^{214} \mathrm{Bi}$ can be significantly overestimated when there is a major presence of ${ }^{222} \mathrm{Rn}$ in the air around the detector. Finally, absorbed dose rate in air values were calculated from the naturally occurring radionuclide concentration in soils. The results showed good correspondence between the values obtained from ISGS and those obtained from laboratory determinations with the same soils.
\end{abstract}

Keywords: In Situ Gamma Spectrometry, Naturally Ocurring Radionuclides, External Gamma Dose Rate, Multiple Peaks Method

\section{Introduction}

The in situ gamma spectrometry (ISGS) technique is a powerful tool for determining the activity concentrations of one or more radionuclides in soils.

Precise knowledge of these concentrations then allows to calculate the dose rate

\footnotetext{
${ }^{1}$ e-mail: corbamer@unex.es
}

Preprint submitted to Elsevier

May 11, 2016

(C) 2016. This manuscript version is made available under the Elsevier user license http://www.elsevier.com/open-access/userlicense/1.0/ 
received from external radiation due to the presence of these radionuclides in the ground. Although this technique consumes far more economical in time and resource consumption than conventional gamma spectrometry, it has the drawback that a series of geometrical approximations have to be made to model the characteristics of the sample, which in this case is the ground. Generally, the sample is assumed to be a flat, unimpeded surface, in which the horizontal distribution of the radionuclides is practically uniform (Baeza and Corbacho, 2005). The depth dependence of the distribution of the radionuclides is assumed to correspond to one of the two commonest cases: homogeneous with depth, or quasi-exponentially decreasing. The former is that used in modeling the distribution of natural radionuclides in soils, while the latter is characteristic of radionuclides that were deposited on the surface layer of soil and have since migrated to deeper layers, provided that the soil has remained undisturbed since that time. There may be a problem in determining ${ }^{214} \mathrm{~Pb}$ and ${ }^{214} \mathrm{Bi}$ activity concentrations with ISGS. The reason is that, since both belong to the ${ }^{238} \mathrm{U}$ series and are daughters of ${ }^{222} \mathrm{Rn}$, they can be present in the air surrounding the detector because of the emanation of this last radionuclide from the soil. The processes of ${ }^{222} \mathrm{Rn}$ emanation depend on a multitude of factors (Sakoda et al., 2011). These include: the content and distribution of radium in the soil; the soil's grain size, porosity, and permeability; its moisture content; the radon diffusion coefficient through fractures and interstitial pores; and the air temperature, inter alia. In ISGS measurements, the ${ }^{222} \mathrm{Rn}$ emanation rate from a soil is assumed to be typically around or below $15 \%$ (ICRU, 1994). Under these conditions, it is partly offset by the contribution of the flux from the same nuclides in the ambient air (Helfer and Miller, 1988). However, depending on the geological characteristics of the soil being measured and on the possible existence of conditions of atmospheric inversion, the emanation rate can be significantly higher. The objective of the present study was, on the one hand, to evaluate the accuracy of ISGS determinations of natural radionuclide activities at a number of geographically separated locations with different types of geology, and therefore with different soil types and, in principle, different exposure rates. And on the other, once the said natural radioactive content had been characterized in situ, to evaluate the total absorbed dose and compare it with that obtained after collecting samples of the same soils and measuring them gamma-spectrometrically at a low-activity laboratory, a technique which has been extensively validated and used worldwide [(UNSCEAR, 2000) Report, and further references cited therein].

\section{Material and Methods}

We selected 15 sites in various parts of Spain which have different geological characteristics. These sites are numbered from 1 to 15 . At each of them, the radioactive content of the soil was measured by ISGS, and a sample of the vertical profile of the soil was collected to a depth of $30 \mathrm{~cm}$. This sample was then measured by conventional gamma spectrometry to determine the changes of the activity concentrations with depth. To determine how the soil's degree 
of relative moisture affects the accuracy of ISGS measurements, we made a series of in situ measurements at the same site at different times of the year, coinciding with the seasons of most and least rainfall. The idea was to establish a relationship between the above cited relative moisture of a soil and the concentration of the descendants of ${ }^{222} \mathrm{Rn}$ and ${ }^{220} \mathrm{Rn}$ in the air. This relationship could then be used to evaluate the accuracy with which the soil's ${ }^{226} \mathrm{Ra}$ activity can be determined from the measurement of its daughters. All the soil samples collected for conventional gamma spectrometry in the laboratory were dried to eliminate their moisture content, and then sieved to a less than $2 \mathrm{~mm}$ grain size. This process allowed the value of the relative moisture level of each sample to be obtained. The dried soil samples were put into $191-\mathrm{cm}^{3}$ volume Petri dishes and sealed to prevent losses from ${ }^{222} \mathrm{Rn}$ emanation. A time of 28 days was allowed for secular equilibrium between ${ }^{226} \mathrm{Ra}$ and its descendants to be re-established. The samples were then measured by conventional low-background gamma spectrometry, using a Ge detector of $45 \%$ relative efficiency housed in 10-cm-thick lead shielding. The detector was calibrated for the geometry used with the soil samples and for the energy range $60-2000 \mathrm{keV}$ using a standard radionuclide cocktail. The systematically analyzed radionuclides were (Energy lines in keV in brackets): ${ }^{212} \mathrm{~Pb}(238.6),{ }^{228} \mathrm{Ac}(338.3 ; 911.0)$, ${ }^{214} \mathrm{~Pb}(352.0),{ }^{208} \mathrm{Tl}(583.1),{ }^{214} \mathrm{Bi}(609.3,1120.3,1764.5),{ }^{40} \mathrm{~K}(1460.7)$. Different reference materials were also used to check the quality of the measurements: IAEA Soil 327 and IAEA Irish Sea Sediment 385 for gamma spectrometry in lab. All test procedures were validated in accordance with the quality requirements of the ISO/IEC 17025 standard (ISO, 2010). The ISGS measurements were made with a portable coaxial intrinsic (hyperpure) Ge detector of $43.1 \%$ relative efficiency, $2.0 \mathrm{keV}$ resolving power, and 1:56 peak-to-Compton ratio for the $1332.5 \mathrm{keV}{ }^{60} \mathrm{Co}$ emission. It was calibrated using the semi-empirical techniques proposed in the literature (Helfer and Miller, 1988). The spectra were acquired for $3600 \mathrm{~s}$, with the detector facing downwards at $1 \mathrm{~m}$ above the ground. For the determination of the soil activity concentration of ${ }^{226} \mathrm{Ra},{ }^{232} \mathrm{Th}$ and ${ }^{40} \mathrm{~K}$, the chosen gamma-emitter radionuclides were respectively: ${ }^{214} \mathrm{~Pb}$ and ${ }^{214} \mathrm{Bi}$ average activity, ${ }^{228} \mathrm{Ac}$ and ${ }^{40} \mathrm{~K}$

\section{Analysis and Results}

\subsection{Determination of the accuracy associated with ISGS measurements of ${ }^{40} \mathrm{~K}$,} ${ }^{226} \mathrm{Ra}$, and ${ }^{232}$ Th in soils: Relationship with relative soil moisture

The calibration factors of ISGS are dependent on the linear attenuation coefficients of soil, $\mu_{s}$, and air, $\mu_{a}$. Given that $\mu_{a}$ is much smaller than $\mu_{s}$, a $10 \%$ variation in $\mu_{a}$ has no significant influence on the calibration factors (Sowa et al., 1989). The ranges of variation of $\mu_{s}$ for various types of soil have been studied and published (ICRU, 1994). At energies below $100 \mathrm{keV}$, there are significant differences in the absorption properties of soils typically used to tabulate ISGS fluence rates. Above this energy, however, the absorption properties are similar. For these higher energies, the value of the mass attenuation coefficient is dominated by Compton scattering, which does not vary much from 
one element to another (ICRU, 1994). For this reason, for many applications the precise soil composition is not needed. However, water present in the soil will attenuate emitted photons before they reach the detector. Moreover, the radon emanation power of a soil depends strongly on its water content (Bossew, 2003). The presence of water in the interstitial spaces between soil particles can favour retention of ${ }^{222} \mathrm{Rn}$ gas, thereby preventing any significant increase in its concentration in the layer of air near the ground. The greater or lesser concentration of radon gas retained in the soil influences the concentration of its daughters $\left({ }^{214} \mathrm{~Pb}\right.$ and $\left.{ }^{214} \mathrm{Bi}\right)$ in the air surrounding the detector. This is one of the causes of the variability in ISGS determinations of soil activity that is important to take into account. We made a series of ISGS measurements at the site corresponding to Soil 9. This soil consists mainly of slate and greywackes. The measurements were made at different times of the year coinciding with the periods of most and least rainfall. At each measurement, a sample of topsoil $(0-5 \mathrm{~cm})$ was taken in order to evaluate its relative moisture. Fig. 1 shows the correlation between the values of the soil's relative moisture and the ratios between the ISGS and conventional laboratory gamma spectrometry determinations of the ${ }^{226} \mathrm{Ra},{ }^{232} \mathrm{Th}$, and ${ }^{40} \mathrm{~K}$ activity concentrations. As can be seen, with decreasing relative moisture of the soil, the gap between the two determinations of the ${ }^{226} \mathrm{Ra}$ activity increases, reaching up to $50 \%$ when the relative moisture of the soil is below $2 \%$. This confirms the reasoning given above that ISGS determinations of soil activity concentrations may be overestimated due to an increased presence of ${ }^{222} \mathrm{Rn}$ and its progeny in the air surrounding the detector, especially when the relative moisture of the soil is very low and hence there is a significant increase of the rate of radon emanation. This aspect needs to be taken into account in arid regions or in those with a marked difference in the accumulated rainfall during summer and winter, as is the case of Mediterranean regions around the world. The behaviour described above was not observed for the ${ }^{232} \mathrm{Th}$ and ${ }^{40} \mathrm{~K}$ radionuclides. Whether in soils with a low relative moisture level $(<10 \%)$ or those with a somewhat higher level, the differences between the two sets of measurements were those inherent to each technique, of the order of $20 \%$.

\subsection{Application of Sowa's method for detecting the concentration of the daugh- ters of ${ }^{222} R n$ in the air around the detector}

Given the problems with ISGS measurements listed in the previous section, it is difficult to know a priori whether one is getting overestimates of ${ }^{226} \mathrm{Ra}$ descendants' activity concentrations without conducting a quantitative evaluation of, inter alia, the soil's geology and relative moisture. However, using the method of Sowa et al. (Sowa et al., 1989), one can identify whether or not there exists an overestimation of the ${ }^{214} \mathrm{~Pb}$ and ${ }^{214} \mathrm{Bi}$ activity concentrations. The multiple peaks method proposed by Sowa et al. (Sowa et al., 1989) is based on the relationship between the different degrees of attenuation experimented by photons emitted at different energies by the same multi-emitting radionuclide. This allows a relationship between the relaxation coefficient $\beta$ and the relative variance of the activity to be established. Then, by varying the value 
of $\beta$, one finds a minimum in the relative variance by a least squares fitting procedure. This allows a procedure to be designed to estimate the systematic error which arises from $\beta$ values that do not correspond to the real radionuclide distribution. The application of this method to the gamma emitting daughters of ${ }^{222} \mathrm{Rn}$ can provide information on their concentration in the air around the detector. When the presence of ${ }^{214} \mathrm{Bi}$ in the air around the detector is negligible compared to that in the ground, the relative variance is minimized for a value of $\beta$ reflecting a uniform distribution of that radionuclide by depth in the soil. Conversely, when the presence of ${ }^{214} \mathrm{Bi}$ in the ambient air is non-negligible with respect to that in the soil, the relationship between the values of the attenuation of the photons emitted at different energies from ${ }^{214} \mathrm{Bi}$ in the air and in the soil is different. Then, the relative variance is minimized for a value of $\beta$ reflecting a non-uniform distribution of ${ }^{214} \mathrm{Bi}$ by depth in the soil, with this result indicating that the ${ }^{214} \mathrm{Bi}$ activity concentration determined for this soil will be overestimated. Based on this working hypothesis, we applied the multiple peaks method to the 15 samples of the soils which we had measured in situ. For this purpose, we used two of ${ }^{214} \mathrm{Bi}$ 's most intense and energy-separated emission lines: $609.3 \mathrm{keV}$ and $1764 \mathrm{keV}$. The $1120 \mathrm{keV}$ line has been discarded due to their proximity to the last ones, and the rest of the energy lines have been discarded due to their weak intensities. The Sowa's method using only two energy lines have been validated by others authors (Korun et al., 1991) (Rybacek et al., 1992). The results (see Table 1) showed that, in those soils in which the value obtained for the coefficient $\beta$ is less than $20 \mathrm{~g} / \mathrm{cm}^{2}$ [Soils 6,7 , 8 , and 9], there are substantial differences in the ${ }^{226} \mathrm{Ra}$ activity concentrations determined in situ (ISGS) and those determined in the laboratory. For the remaining sampling sites, where the said coefficient is greater than $50 \mathrm{~g} / \mathrm{cm}^{2}$, the ratio (ISGS/Lab) between the ${ }^{226} \mathrm{Ra}$ activity concentrations obtained with ISGS and those obtained conventionally in the laboratory is practically unity. By way of example, fig. 2 shows the ${ }^{214} \mathrm{Bi}$ depth profiles obtained for Soil 2 and Soil 8 from laboratory measurements of six subsamples of each soil collected at different depths, and the relationship between the relative variance and the relaxation coefficient, $\beta$, obtained by the multiple peaks method. The Soil 2 sampling point is in an area of predominantly clay soils with a small grain size and high water holding capacity. Conversely, the Soil 8 sampling point is located in an area of sandy soils on an arkose substrate. It thus has larger grain sizes than Soil 2 and a lower water holding capacity, and consequently a higher rate of ${ }^{222} \mathrm{Rn}$ emanation. One observes in the figure that, for Soil 2, the relative variance is minimized for a value of $\beta$ around $80 \mathrm{~g} / \mathrm{cm}^{2}$, indicating that in this case the presence of ${ }^{214} \mathrm{Bi}$ in the air surrounding the detector is insignificant compared to that in the ground, and therefore that there will be no overestimate in the ISGS determination of ${ }^{226} \mathrm{Ra}$ from its daughters. Conversely, for Soil 8 , the value of the relative variance is minimized for a value of $\beta$ close to $10 \mathrm{~g} / \mathrm{cm}^{2}$, indicating that the in situ measurement of the soil's ${ }^{214} \mathrm{Bi}$ activity concentration will be overestimated. This is verified by the ISGS/Lab ratios given in Table 1 . The ISGS determination of the ${ }^{226}$ Ra concentration is clearly overestimated, with the magnitude of the overestimation being by a factor of 
from 1.7 to 3.2 depending on the soil's relative moisture content.

The conclusion to be drawn is that the determination by ISGS of ${ }^{226} \mathrm{Ra}$ from its daughters ${ }^{214} \mathrm{Bi}$ and ${ }^{214} \mathrm{~Pb}$ can lead to an overestimate of its activity, and that this overestimate is difficult to quantify since it depends on numerous factors, including the ${ }^{222} \mathrm{Rn}$ emanation rate, the soil's relative moisture content or geology, which initially are not usually quantified in situ. Nevertheless, if the soil being measured has not been altered, the vertical distribution of natural radionuclides should be homogeneous. Under these conditions, it is useful to apply the multiple peaks method to determine the ${ }^{214} \mathrm{Bi}$ activity so as to detect whether it is present significantly in the air around the detector due to a high ${ }^{222} \mathrm{Rn}$ emanation rate from the ground. One can conclude from the present results that if the relaxation coefficient $\beta$ obtained by applying the multiple peaks method to the ${ }^{214} \mathrm{Bi}$ emission lines is less than $20 \mathrm{~g} / \mathrm{cm}^{2}$ then the activity of this radionuclide will be overestimated. In consequence, therefore, the value of the ${ }^{226} \mathrm{Ra}$ activity determined from the average of the in situ measurements of the ${ }^{214} \mathrm{Bi}$ and ${ }^{214} \mathrm{~Pb}$ activities, will be an overestimate of the real value by factors ranging from 1.5 to 3 .

3.3. Determination of the accuracy in the measurement by ISGS of ${ }^{40} K,{ }^{226} R a$, and ${ }^{232}$ Th in soils

Table 1 gives the activity concentrations and the ISGS/Lab ratios for the activities of the radionuclides ${ }^{40} \mathrm{~K},{ }^{232} \mathrm{Th}$, and ${ }^{226} \mathrm{Ra}$. Figure 3 shows the correlations between the activity concentrations measured by the two techniques for each of the aforecited radionuclides. One observes in the table and the figure that there is a strong correlation between these two sets of activities for the radionuclides considered. This is confirmed by the linear regression lines shown for each of the plots of fig. 3. It is noteworthy that, for the ${ }^{40} \mathrm{~K}$ and ${ }^{232} \mathrm{Th}$ activities, the coefficient of determination, $\mathrm{r}^{2}$, is greater than 0.94. However, as it was detailed in the preceding sections, this coefficient is slightly lower for the case of the ${ }^{226} \mathrm{Ra}$ activity, 0.85 , indicating that the correlation between the results yielded by the two techniques is weaker. This is due to the overestimation of the ${ }^{214} \mathrm{~Pb}$ and ${ }^{214} \mathrm{Bi}$ activity in some of the in situ determinations as a result of their high concentrations in the air surrounding the detector.

In view of the results, one can assume that, for ${ }^{40} \mathrm{~K}$ and ${ }^{232} \mathrm{Th}$, the differences between the ISGS and the conventional measurements are around or below $15 \%$, with the exception of the measurements made on sandy soils, when the differences can reach up to $30 \%$. This is not the case with the ${ }^{226} \mathrm{Ra}$ concentration, whose value is deduced indirectly as an average of the measured concentrations of ${ }^{214} \mathrm{~Pb}$ and ${ }^{214} \mathrm{Bi}$. For soils 6,7 , and 8 , the activity concentrations registered using ISGS may differ, depending on the relative moisture of the soil, by a factor of up to 3 with respect to the laboratory determinations. It should be noted that the observed outlier value corresponds to the sample Soil 7. This sample was collected in an area due to its geological characteristics present, under certain conditions, a relatively significant ${ }^{222} \mathrm{Rn}$ exhalation rates (Poncela et al., 2005). For the other soils however, the differences do not exceed $15 \%$, with the exception of Soils 11 and 12 for which they reach $30 \%$. 
With regard to the type of geology of the soils analysed, the sandy soils, such as those on an arkose substrate, present the greatest difference between the ISGS and the conventional laboratory measurements of the activity concentrations. A particularity of this soil type is the high proportion of air space between the grains. This significantly influences the ${ }^{222} \mathrm{Rn}$ emanation rate, which increases when the moisture content is low. For all these reasons, it can be stated qualitatively that, in the presence of sandy soils, the activity concentrations registered by the ISGS technique may be affected by overestimates of about $30 \%$.

\subsection{Calculation of the absorbed dose in air from the measured concentrations of natural radionuclides}

We determined the absorbed dose rate in air (ADA) for the soils analysed from the ${ }^{40} \mathrm{~K},{ }^{232} \mathrm{Th}$, and ${ }^{226} \mathrm{Ra}$ activity measurements that were made using both the ISGS and the conventional laboratory techniques. For this, we used Equation (1), given by Quindos et al. (Quindos et al., 2004):

$$
A D A(n G y / h)=0.4551 \cdot C_{R a}+0.5835 \cdot C_{T h}+0.0429 \cdot C_{K}
$$

In this expression, $\mathrm{C}_{K}, \mathrm{C}_{R a}$, and $\mathrm{C}_{T h}$ are the concentrations in $\mathrm{Bq} / \mathrm{kg}$ of ${ }^{40} \mathrm{~K}$, ${ }^{226} \mathrm{Ra}$, and ${ }^{232} \mathrm{Th}$, respectively. In calculating the values of ADA, we took into account for Soils 6 and 8 the two measurements made with different degrees of relative soil moisture content. As can be seen in fig. 4, there is a strong correlation between the ADA values obtained by the two techniques. This is confirmed by the values of the linear regression coefficients $(\mathrm{y}=\mathrm{mx}+$ $\mathrm{n} ; \mathrm{m}=1.05 \pm 0.5 ; \mathrm{n}=-(15 \pm 26) 10^{-4} ; \mathrm{r}^{2}=0.95$. $)$ It is important to note that the variation of the ADA in the ISGS measurements that are affected by large overestimates of the ${ }^{226} \mathrm{Ra}$ activity concentrations due to the significant presence of ${ }^{222} \mathrm{Rn}$ in the air is of the order of $12 \%-36 \%$. This is a fact that has to be taken into account when determining the absorbed dose rate in air from measurements made using the IGSG technique.

\section{Conclusions}

There is a significant correspondence between the values of the natural radionuclide activity concentrations in soils as measured by the ISGS technique and by conventional laboratory gamma spectrometric techniques. In general, it can be assumed that there may be differences of up to $15 \%$ for the activity concentrations of the ${ }^{40} \mathrm{~K}$ and ${ }^{232} \mathrm{Th}$ radionuclides, with the exception of sandy soils such as those on an arkose substrate in which the differences may reach $30 \%$ when there is very little moisture in the soil. The ISGS determination of the ${ }^{226} \mathrm{Ra}$ activity from its daughters ${ }^{214} \mathrm{~Pb}$ and ${ }^{214} \mathrm{Bi}$ in secular equilibrium may have an additional problem since the concentration in the air between the detector and the soil of these last two radionuclides it cannot be considered negligible compared to the concentration in the soil. This is especially likely in measurements of soils where there is a high level of ${ }^{222} \mathrm{Rn}$ emanation, as in situations where different factors coincide, such as sandy soils with low levels 
of relative moisture content. In such situations, the in situ measurements may overestimate the real values of the ${ }^{214} \mathrm{~Pb}$ and ${ }^{214} \mathrm{Bi}$ activity concentrations by up to a factor of 3. Given the difficulty of identifying and quantifying these factors so as to find a correction factor, our suggestion is that Sowa et al.'s multiple peaks method could be used to identify whether or not this type of overestimate will occur. This method is based on the relationship between the different degrees of attenuation undergone by photons emitted at different energies by each of the radionuclides ${ }^{214} \mathrm{~Pb}$ and ${ }^{214} \mathrm{Bi}$. In any case, the ADA values calculated with data from the ISGS technique have a strong correspondence with those obtained from gamma spectrometry measurements of the same soil in the low background laboratory. The greatest differences found, of around $30 \%$, are linked exclusively to the determination of the daughters of the ${ }^{238} \mathrm{U}$ series for the reasons discussed above.

\section{Acknowledgments}

This work was made possible thanks to funding received by the LARUEX (FQM001) research group from the Regional Government of Extremadura in its V Regional R\&D+i Plan, DOE N 5 of 09.01.2014.

\section{References}

\section{References}

Baeza, A., Corbacho, J., 2005. Comparative analysis of the in and ex situ determination of environmental radiation and dosimetry levels. Radiation protection dosimetry 113 (1), 90-98.

Bossew, P., 2003. The radon emanation power of building materials, soils and rocks. Applied radiation and isotopes 59 (5), 389-392.

Helfer, I. K., Miller, K. M., 1988. Calibration factors for Ge detectors used for field spectrometry. Health Physics 55 (1), 15-29.

ICRU, 1994. In Situ Gamma-ray Spectrometry in the Environment. Tech. rep.

ISO, 2010. Determination of the characteristic limits (decision threshold, detection limit and limits of the confidence interval) for measurements of ionizing radiation - Fundamentals and application. Tech. Rep. ISO/DIS 11929.

Korun, M., Martinčič, R., Pucelj, B., 1991. In-situ measurements of the radioactive fallout deposit. Nuclear Instruments and Methods in Physics Research Section A: Accelerators, Spectrometers, Detectors and Associated Equipment $300(3), 611-615$.

Poncela, L. Q., Navarro, P. F., Fernández, C. S., Matarranz, J. M., García, J. A., 2005. Natural radiation exposure in the Campo Aranuelo region in the surroundings of Almaraz nuclear power station (Spain). Journal of environmental radioactivity 79 (3), 347-354. 
Quindos, L., Fernandez, P., Rodenas, C., Gomez-Arozamena, J., Arteche, J., 2004. Conversion factors for external gamma dose derived from natural radionuclides in soils. J. Environ. Radioactiv. 71 (2), 139-145.

Rybacek, K., Jacob, P., Meckbach, R., 1992. In Situ Determination of Deposited Radionuclide Activities: Improved Method Using Derived Depth Distributions From the Measured Photon Spectra. Health physics 62 (6), 519-528.

Sakoda, A., Ishimori, Y., Yamaoka, K., 2011. A comprehensive review of radon emanation measurements for mineral, rock, soil, mill tailing and fly ash. Applied Radiation and Isotopes 69 (10), 1422-1435.

Sowa, W., Martini, E., Gehrcke, K., Marschner, P., Naziry, M., 1989. Uncertainties of in situ gamma spectrometry for environmental monitoring. Radiation Protection Dosimetry 27 (2), 93-101.

UNSCEAR, 2000. Sources and effects of ionizing radiation. United Nations Scientific Committee on the Effects of Atomic Radiation. Tech. rep.

[Figure 1 about here.]

[Figure 2 about here.]

[Figure 3 about here.]

[Figure 4 about here.]

[Table 1 about here.] 


\section{List of Figures}

1 Correlation between the soil's relative moisture content and the ratio between the ${ }^{226} \mathrm{Ra},{ }^{232} \mathrm{Th}$, and ${ }^{40} \mathrm{~K}$ activities determined by in situ spectrometry and by conventional techniques in the laboratory. . . . . . . . . . . . . . . . . 11

2 Up: Relationship between the relative variance of ${ }^{214} \mathrm{Bi}$ 's activity and the relaxation coefficient $\beta$ for Soil 2 (circles) and Soil 8 (black squares). Down: Depth profile of the concentration of ${ }^{214} \mathrm{Bi}$ at the sites of Soil 2 (circles) and Soil 8 (black squares). . . . . . . . 12

3 Correlation between the activity concentrations determined in the laboratory and those determined by ISGS. Solid line: $\mathrm{y}=\mathrm{x}$. Dashed line: Linear fit to the data. . . . . . . . . . . . . . . 13

4 Ratio between the absorbed dose rates in air as determined from the concentrations of ${ }^{226} \mathrm{Ra},{ }^{232} \mathrm{Th}$, and ${ }^{40} \mathrm{~K}$ found by conventional techniques for collecting the soil sample followed by its gamma measurement in the laboratory (Lab) and the same absorbed dose rates in air determined from the concentrations of ${ }^{226} \mathrm{Ra},{ }^{232} \mathrm{Th}$, and ${ }^{40} \mathrm{~K}$ found by in situ gamma spectrometry (ISGS). . . . . . . . . . . . . . . . . . . 14 


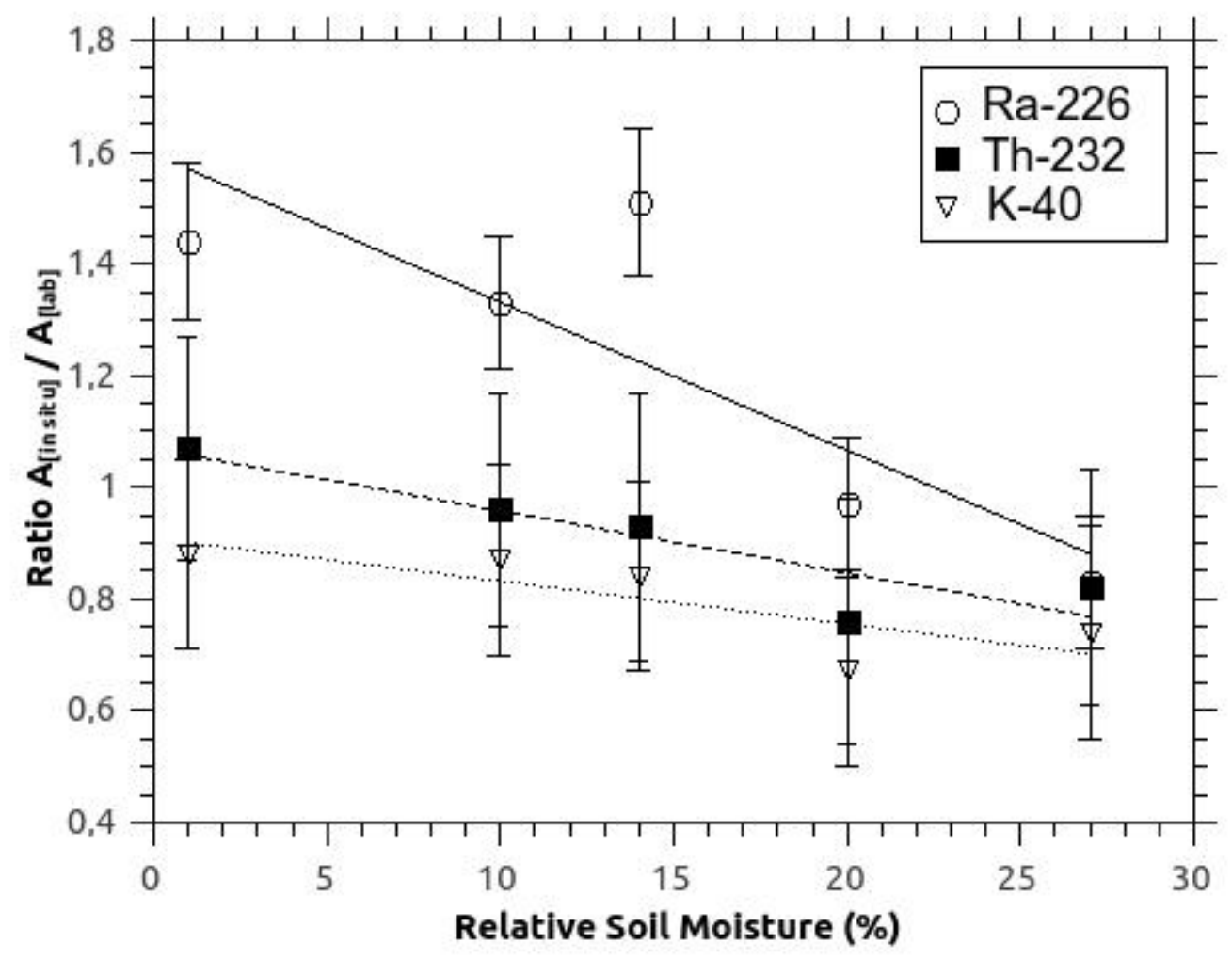

Figure 1: Correlation between the soil's relative moisture content and the ratio between the ${ }^{226} \mathrm{Ra},{ }^{232} \mathrm{Th}$, and ${ }^{40} \mathrm{~K}$ activities determined by in situ spectrometry and by conventional techniques in the laboratory. 

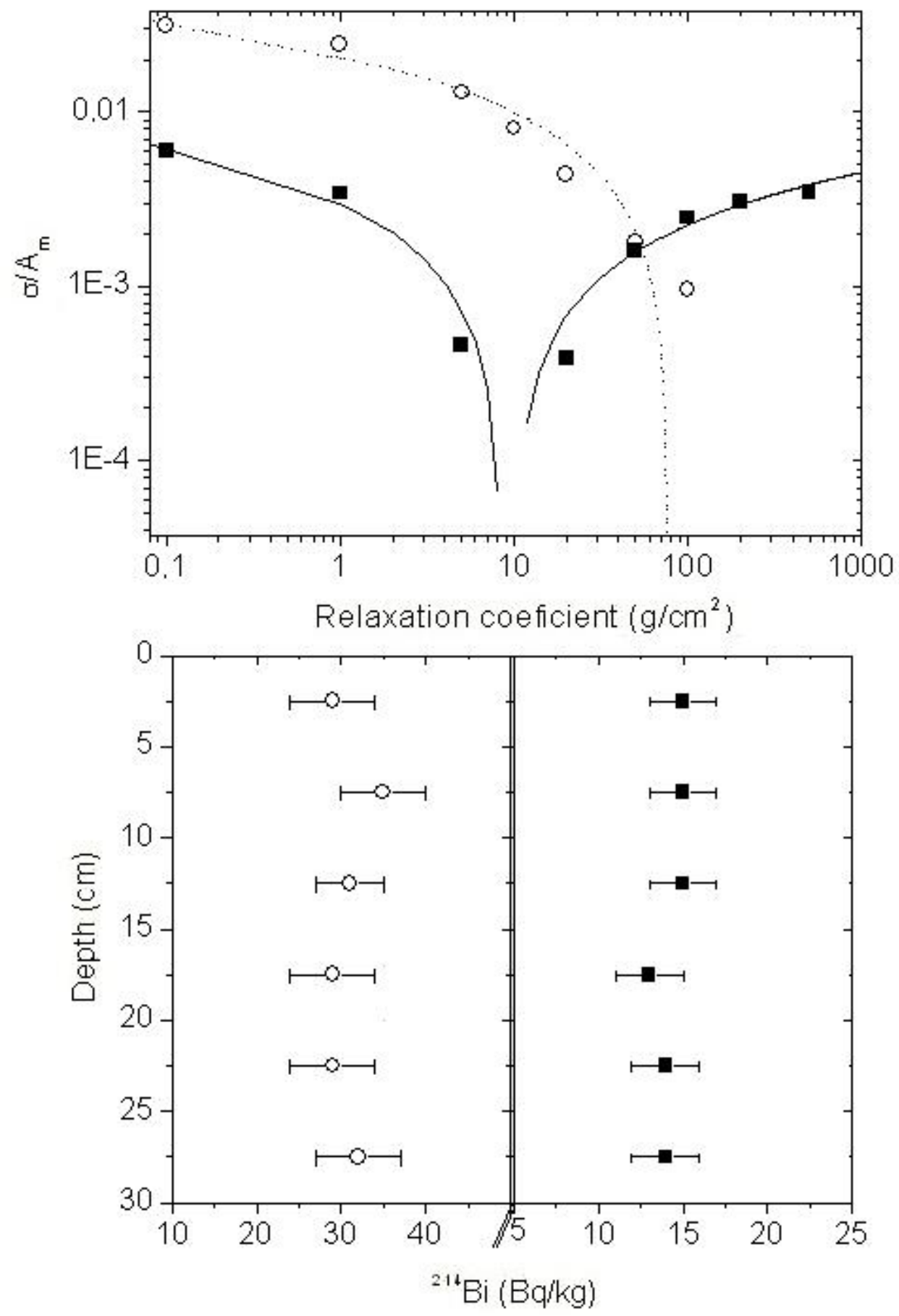

Figure 2: Up: Relationship between the relative variance of ${ }^{214} \mathrm{Bi}$ 's activity and the relaxation coefficient $\beta$ for Soil 2 (circles) and Soil 8 (black squares). Down: Depth profile of the concentration of ${ }^{214} \mathrm{Bi}$ at the sites of Soil 2 (circles) and Soil 8 (black squares). 

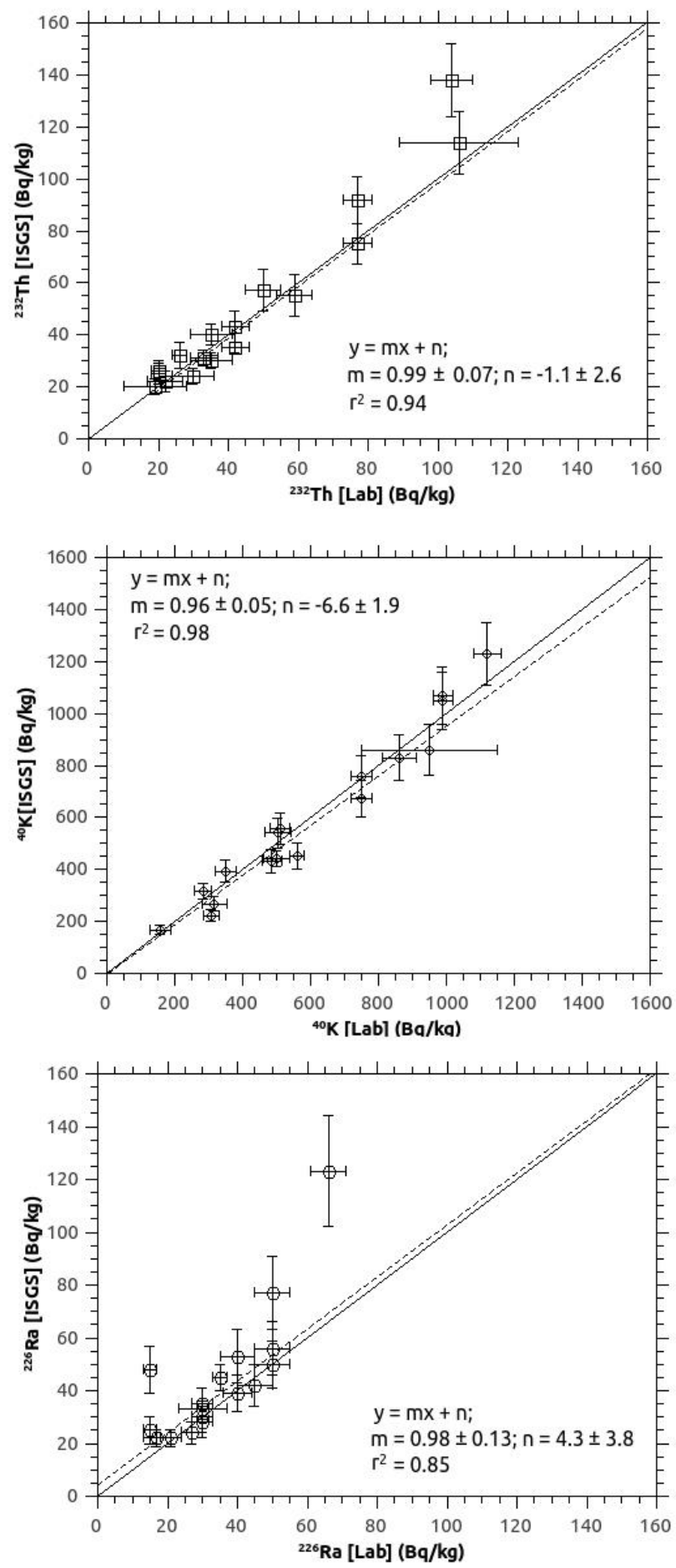

Figure 3: Correlation between the activity concentrations determined in the laboratory and those determined by ISGS. Solid line: $\mathrm{y}=\mathrm{x}$. 113ashed line: Linear fit to the data. 


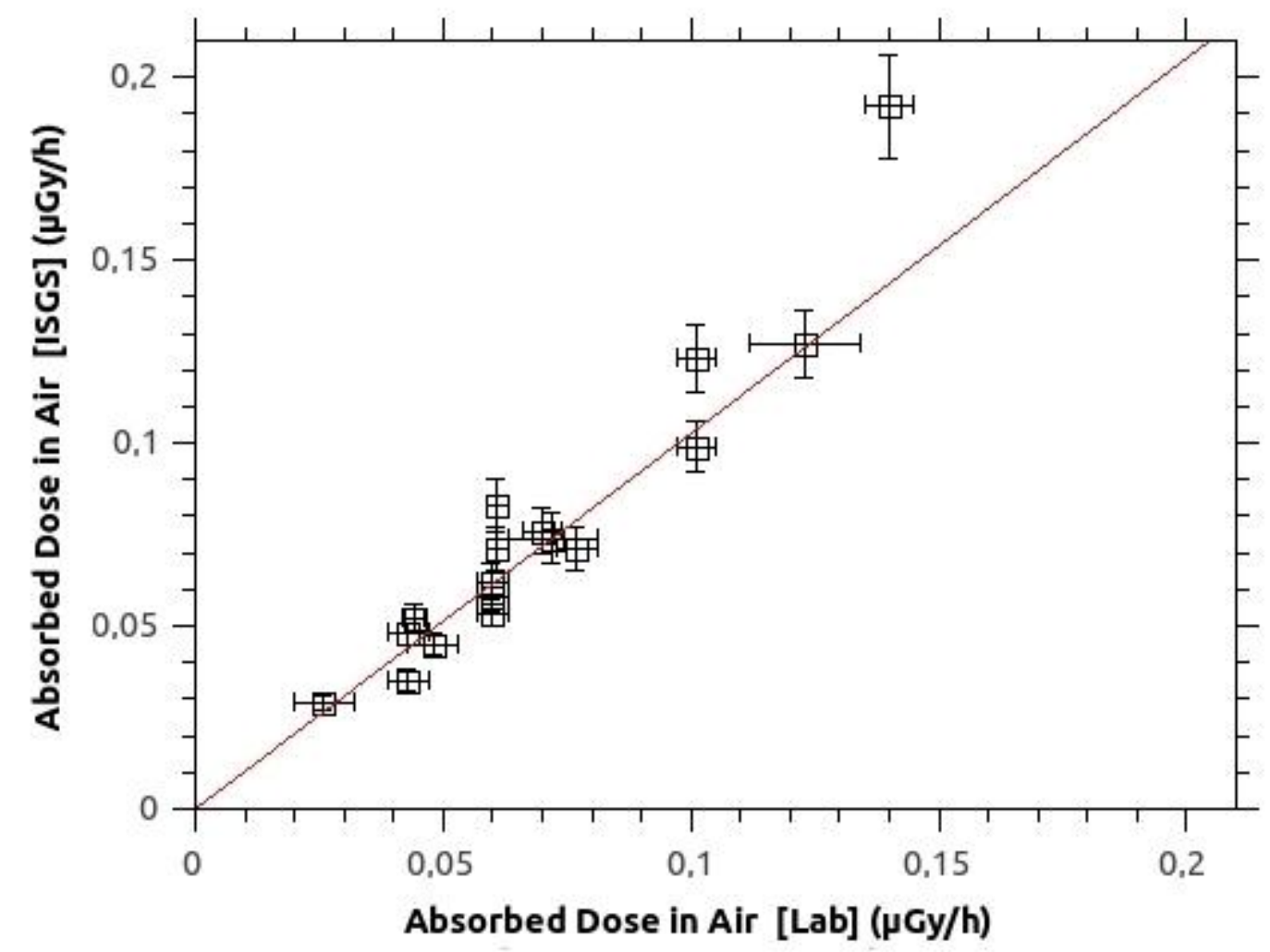

Figure 4: Ratio between the absorbed dose rates in air as determined from the concentrations of ${ }^{226} \mathrm{Ra},{ }^{232} \mathrm{Th}$, and ${ }^{40} \mathrm{~K}$ found by conventional techniques for collecting the soil sample followed by its gamma measurement in the laboratory (Lab) and the same absorbed dose rates in air determined from the concentrations of ${ }^{226} \mathrm{Ra},{ }^{232} \mathrm{Th}$, and ${ }^{40} \mathrm{~K}$ found by in situ gamma spectrometry (ISGS). 
345 List of Tables

3461 Geological characteristics and relative moisture content of the 347 soils sampled. Natural radionuclide activity concentrations de348 termined in situ and by laboratory measurements of samples of 349 the soils. Ratio between the activity measured in situ and that $350 \quad$ obtained in the laboratory. The coefficient $\beta$ determined for the ${ }_{351}^{214} \mathrm{Bi}$ activity by the technique of Sowa et al. $(*)$ Measurements $352 \quad$ made later at the same site, but after a continued period of rain.

Relative moisture of the soil $>25 \%$. . . . . . . . . 16 
Table 1: Geological characteristics and relative moisture content of the soils sampled. Natural radionuclide activity concentrations determined in situ and by laboratory measurements of samples of the soils. Ratio between the activity measured in situ and that obtained in the laboratory. The coefficient $\beta$ determined for the ${ }^{214} \mathrm{Bi}$ activity by the technique of Sowa et al. $\left(^{*}\right)$ Measurements made later at the same site, but after a continued period of rain. Relative moisture of the soil $>25 \%$.

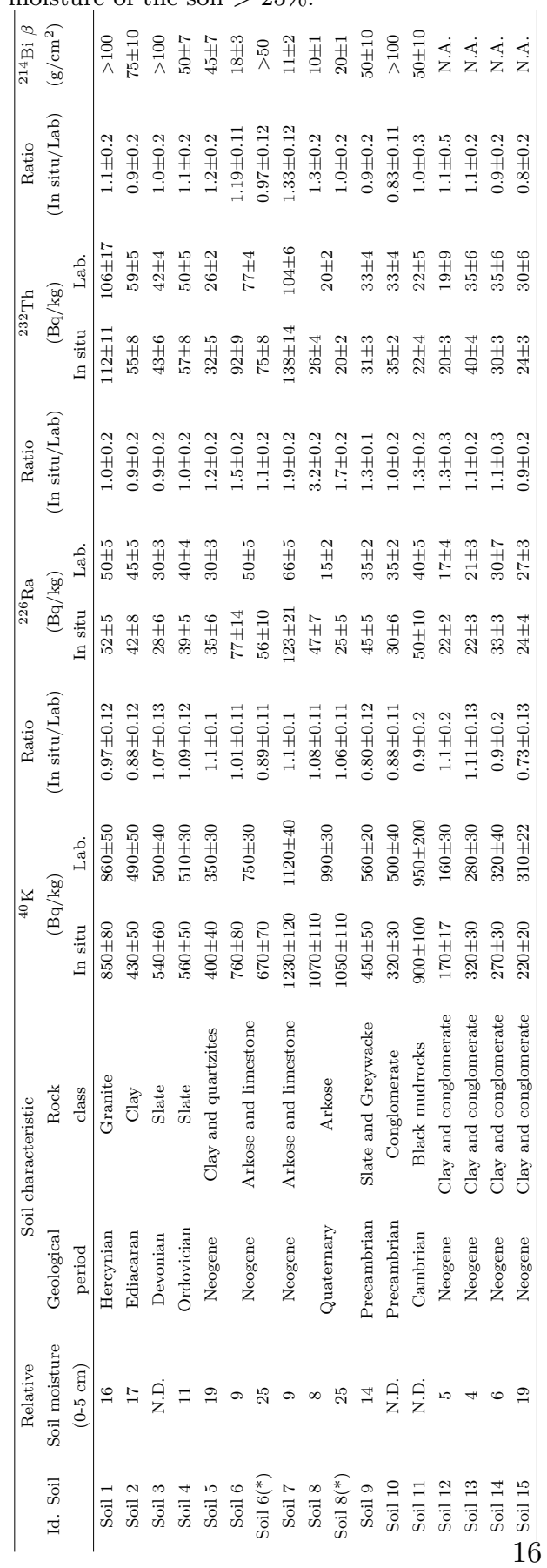

